\title{
Potential of Mesenchymal Stem Cell-Derived Exosomes as a Novel Treatment for Female Infertility Caused by Bacterial Infections
}

\begin{abstract}
Marzieh Zohrabi',2, Laleh Dehghan Marvast ${ }^{3}$, Mahin Izadi',2, Seyed Alireza Mousavi ${ }^{4}$ and Behrouz Aflatoonian $2,5,6 *$

${ }^{1}$ Research and Clinical Center for Infertility, Yazd Reproductive Sciences Institute, Shahid Sadoughi University of Medical Sciences, Yazd, Iran, ${ }^{2}$ Department of Reproductive Biology, School of Medicine, Shahid Sadoughi University of Medical Sciences, Yazd, Iran, ${ }^{3}$ Andrology Research Center, Yazd Reproductive Sciences Institute, Shahid Sadoughi University of Medical Sciences, Yazd, Iran, ${ }^{4}$ Infectious Diseases Research Center, Shahid Sadoughi Hospital, Shahid Sadoughi University of Medical Sciences, Yazd, Iran, ${ }^{5}$ Stem Cell Biology Research Center, Yazd Reproductive Sciences Institute, Shahid Sadoughi University of Medical Sciences, Yazd, Iran, ${ }^{6}$ Department of Advanced Medical Sciences and Technologies, School of Paramedicine, Shahid Sadoughi University of Medical Sciences, Yazd, Iran
\end{abstract}

OPEN ACCESS

Edited by:

Nader Tanideh,

Shiraz University of Medical Sciences,

Iran

Reviewed by:

Ulanbek Zhanbyrbekuly,

Astana Medical University,

Kazakhstan

Jafar Rezaie,

Urmia University of Medical Sciences,

Iran

*Correspondence:

Behrouz Aflatoonian

b.aflatoonian@ssu.ac.ir

Specialty section: This article was submitted to Antimicrobials, Resistance and Chemotherapy,

a section of the journal

Frontiers in Microbiology

Received: 29 September 2021 Accepted: 08 December 2021 Published: 27 January 2022

Citation:

Zohrabi M, Dehghan Marvast L,

Izadi M, Mousavi SA and

Aflatoonian B (2022) Potential

of Mesenchymal Stem Cell-Derived

Exosomes as a Novel Treatment for Female Infertility Caused by

Bacterial Infections.

Front. Microbiol. 12:785649. doi: 10.3389/fmicb.2021.785649
Neisseria gonorrhoeae and Chlamydia trachomatis are the most common causes of bacterial sexually transmitted diseases (STDs) with complications in women, including pelvic inflammatory disease (PID), ectopic pregnancy, and infertility. The main concern with these infections is that $70 \%$ of infected women are asymptomatic and these infections ascend to the upper female reproductive tract (FRT). Primary infection in epithelial cells creates a cascade of events that leads to secretion of pro-inflammatory cytokines that stimulate innate immunity. Production of various cytokines is damaging to mucosal barriers, and tissue destruction leads to ciliated epithelial destruction that is associated with tubal scarring and ultimately provides the conditions for infertility. Mesenchymal stem cells (MSCs) are known as tissue specific stem cells with limited self-renewal capacity and the ability to repair damaged tissues in a variety of pathological conditions due to their multipotential differentiation capacity. Moreover, MSCs secrete exosomes that contain bioactive factors such as proteins, lipids, chemokines, enzymes, cytokines, and immunomodulatory factors which have therapeutic properties to enhance recovery activity and modulate immune responses. Experimental studies have shown that local and systemic treatment of MSC-derived exosomes (MSC-Exos) suppresses the destructive immune response due to the delivery of immunomodulatory proteins. Interestingly, some recent data have indicated that MSC-Exos display strong antimicrobial effects, by the secretion of antimicrobial peptides and proteins (AMPs), and increase bacterial clearance by enhancing the phagocytic activity of host immune cells. Considering MSC-Exos can secrete different bioactive factors that can modulate the immune system and prevent infection, exosome therapy is considered as a new therapeutic method in the treatment of inflammatory and microbial diseases. Here we intend to review the possible application of MSC-Exos in female reproductive system bacterial diseases.

Keywords: antimicrobial effects, mesenchymal stem cells, MSC-derived exosomes, antibacterial properties, Neisseria gonorrhoeae, Chlamydia trachomatis, female infertility 


\section{INTRODUCTION}

Today, with the huge concern regarding antibiotic resistance and due to absence of an effective vaccine, researchers are looking for suitable alternatives to solve this problem (Hosseiniyan Khatibi et al., 2020; Russell et al., 2020). Mesenchymal stem cells (MSCs) are defined as undifferentiated renewable cells. These cells can be isolated from different tissues including bone marrow, cord blood, skin, fallopian tube, liver, lungs, endometrium, testis, amnion, ovary, and adipose tissue (Akyash et al., 2016a,b; Sadeghian-Nodoushan et al., 2016; Zhang et al., 2016; Akyash et al., 2020; Hoseini et al., 2020). Moreover, there are reports indicating the generation of MSCs from pluripotent human embryonic stem cells (hESCs) (Akyash et al., 2016a; Javidpou et al., 2021). The therapeutic potentials of MSCs are accomplished through three mechanisms. The first is differentiation into multiple cell types, which provides the condition for repairing and replacing damaged tissues. The second is that MSCs migrate to injured tissues due to chemical gradients. The third mechanism is the most important mechanism due to secretion of bioactive factors (Vizoso et al., 2017). Moreover, MSCs are able to secrete nanoparticles called exosomes that from by fusion of the cell membrane of multivesicular and are considered as extracellular vesicles (EVs). EVs according to International Society for Extracellular Vesicles (ISEV) are divided into three classes based on their size and origin, which include exosomes, microvesicles (MVs), and apoptotic bodies; (a) exosomes with various in size of 30-150 nm originate from multivesicular bodies (MVBs), (b) microvesicles in size of $150-1000 \mathrm{~nm}$, (c) apoptotic bodies with a wide size distribution of 50-2000 nm (Gurunathan et al., 2019; Akbari and Rezaie, 2020; Rezaie et al., 2021). Studies show that MSCs exert their paracrine effects by secreting exosomes which are known by other names including nanoparticles, exosomelike vesicles, dexosomes, prostasomes, and tolerosomes (Zhang et al., 2020; Rezaie et al., 2021). Exosomes are transitional vesicles that release into the extracellular space through fusion with the cell membrane, which can reach distance target cells and affect their function and activity (Kowal et al., 2014). MSC-derived exosomes (MSC-Exos) are able to secrete cytokines, chemokines, and growth factors, proteins, mRNA, non-coding RNA, and bioactive lipids that could elicit a wide range of physiological activities (Harrell et al., 2019; Adib et al., 2020b,a; Yuan et al., 2020). Moreover MSC-Exos are considered as an innovative therapeutic tool to treat bacterial infections, consistent with their unique properties (Park et al., 2019). Neisseria gonorrhoeae (N. gonorrhoeae) and Chlamydia trachomatis (C. trachomatis) are gram-negative bacteria that are both considered as obligate human pathogens (Chen et al., 2018). Due to the pathogenesis of $N$. gonorrhoeae and C. trachomatis and the ability of these bacteria to cause chronic infections and, on the other hand, considering the side effects of antibiotic resistance and the absence of effective vaccines, new treatment strategies are needed to repair damaged epithelial cells of fallopian tube (FT) in these infections. As regards conditioned medium (CM) or MSC-Exos contain growth factors, antimicrobial peptides/proteins (AMPs) and cytokines have immunosuppression properties on innate and adaptive immune responses via direct and indirect mechanisms.
In addition, CM and MSC-Exos have other therapeutic potentials including anti-apoptotic activity, wound healing, tissue repair, antiscarring, and angiogenesis regulation (Burlacu et al., 2013; Williams et al., 2013; Vizoso et al., 2017; Adib et al., 2020b,a), Here, we intend to review the application of MSC-Exos in female reproductive system bacterial diseases.

\section{ANTIMICROBIAL EFFECTS OF MESENCHYMAL STEM CELLS}

Many studies have shown that MSCs display antimicrobial features by secretion of AMPs and regulation of immune responses (Krasnodembskaya et al., 2010; Koniusz et al., 2016). These antimicrobial effects of MSCs are mediated via direct and indirect mechanisms (Russell et al., 2020). MSCs directly interact with pathogens by secreting AMPs, including lipocalin 2 , cathelicidin, $\beta$-defensin 2 , and hepcidin, thereby playing an important role in increasing bacterial clearance (Marrazzo et al., 2019; Chow et al., 2020). While MSCs are exposed to pathogenic factors, including pathogen-associated molecular patterns (PAMPs), lipopolysaccharide (LPS), and damage-associated molecular patterns (DAMPs) via toll-like receptors (TLRs), caused a change in their proliferation, differentiation, migration, and secretory factors (Marrazzo et al., 2019; Hosseiniyan Khatibi et al., 2020). The immunomodulatory effects of MSC-Exos are mainly due to inhibition of $\mathrm{T}$ cells proliferation and conversion of these cells to regulatory $\mathrm{T}$ cells (Tregs) and also through reprogramming of M1 macrophage cells to M2 phenotype that these immunomodulatory and antiinflammatory effects of MSC-Exos lead to tissue repair and healing (Xie et al., 2020; Arabpour et al., 2021).

\section{Direct Mechanisms}

Antimicrobial peptides and proteins secreted from the MSC directly play important roles in the bacteria clearance from different pathways, including inhibition in the synthesis of DNA and RNA, disruption of membrane integrity, and inhibition of bacterial growth through disruption in iron uptake (Brogden, 2005; Hosseiniyan Khatibi et al., 2020). AMPs are produced as the first line of defense of innate immunity against a wide range of microorganisms, including bacteria, viruses, and fungi (Diamond et al., 2009). Families of MSCs-derived AMPs listed in Figure $\mathbf{1}$ are mainly studied including cathelicidin, $\beta$-defensin-2, lipocalin 2, and Hepcidin (Alcayaga-Miranda et al., 2017; Russell et al., 2020).

\section{Cathelicidin}

One of the important antibacterial peptides is the cathelicidin family, which recruits monocytes, neutrophils, and macrophages (Krasnodembskaya et al., 2010). LL-37 is a factor of this family that is an essential part of the innate immune system that exerts its antibacterial effect by disrupting the integrity of the bacterial membrane and neutralizing LPS (Krasnodembskaya et al., 2010; Thennarasu et al., 2010). This factor has also been shown to play an important role in regulating inflammatory responses, inducing tissue repair and healing as well as anti-apoptotic and 
angiogenic effects (Oliveira-Bravo et al., 2016; Yang et al., 2020), and in a mouse model of septicemia provided protection against endotoxin shock (Yagi et al., 2020). Johnson et al. (2017), in a study of the antibacterial effects of MSC administration in chronic infections associated with biofilms in mouse and dog models, stated that i.v. administration of activated MSCs induce the killing of bacteria by secretion of cathelicidin, and this effect was increased by antibiotics.

\section{$\beta$-Defensin 2}

$\beta$-defensin 2 play important roles in innate and adaptive immunity against microbial and exert its antibacterial effect by creating pores in the bacterial membrane and destroying the integrity of the membrane and leaking intracellular contents, as well as inhibiting protein, DNA, and RNA syntheses (Laverty et al., 2011; Méndez-Samperio, 2013). A study showed that MSCs secrete the antimicrobial peptide of $\beta$-defensin 2 through the TLR-4 signaling pathway after exposure to Escherichia coli (Sung et al., 2016). The bacteriostatic potential of this peptide is mainly against gram-negative bacteria and with a lower antibacterial potential against gram-positive bacteria (Harder and Schröder, 2005).

\section{Lipocalin 2}

Lipocalin 2 is secreted by various cells including neutrophils, macrophages, epithelial cells, and MSCs in response to inflammatory conditions, which plays an important role in the antibacterial defense of the innate immunity (Dahl et al., 2018). After exposure of MSCs to pathogenic factors lead to the secretion of a large amount of lipocalin 2, this peptide binds to siderophore, as an iron chelator of bacteria, which in turn prevents iron uptake and subsequently reduces bacterial growth (Goetz et al., 2002; Flo et al., 2004). Harman et al. (2017) reported that MSCs derived from the peripheral blood of healthy horses by the secretion of AMPs, including Cystatin C, elafin, lipocalin, and cthelicidin, through disturbance in membrane integrity, the growth of bacteria (E. coli and Staphylococcus aureus) was inhibited.

\section{Hepcidin}

Hepcidin is secreted by hepatocytes, renal epithelial cells, as well as by macrophages and MSCs in inflammatory conditions, which plays an important role in the systemic regulation of iron homeostasis (Kulaksiz et al., 2004, 2005; Esfandiyari et al., 2019). Hepcidin is an antibacterial peptide of the innate immune system that is primarily induced by the IL-6, LPS, and TLR-4 which sequesters bacterial siderophores, and therefore restricts iron availability and as a result inhibits bacterial growth (Ganz and Nemeth, 2012; Michels et al., 2017). Two isoforms of hepcidin are known, including hepcidin 20 and 25, both of which have antibacterial properties (Maisetta et al., 2010).

\section{Inducible Nitric Oxide Synthase Pathway}

Mesenchymal stem cells and macrophages activated by LPS, pro-inflammatory cytokines, and interferons (IFN) cause the expression of inducible nitric oxide synthase (iNOS), which in turn iNOS produces nitric oxide (NO) from the amino acid $\mathrm{L}$-arginine inside these cells. Production of NO in this way halts the growth of microorganisms inside macrophages and MSCs (Bogdan, 2015; Yang et al., 2016).

\section{Cysteine Proteases}

Studies show that MSC-Exos contain a variety of proteases, including cysteine proteases, which impact the stability of bacterial biofilms by degrading extracellular proteins, and thereby provide conditions for antimicrobials penetration into biofilms and also increase the effectiveness of antibiotics tolerated by biofilms previously (Matsumoto et al., 1999; Marx et al., 2020).

\section{Indoleamine 2,3 Dioxygenase}

Indoleamine 2,3 dioxygenase (IDO) is the most important enzyme in the kynurenine pathway (KP), which is primarily responsible for the degradation of the tryptophan amino acid, which MSCs mainly express this enzyme in response to the stimulatory effect of INF $\gamma$ (Däubener et al., 2009; Croitoru-Lamoury et al., 2011). Depletion of tryptophan in microorganisms due to IDO impairs protein synthesis and disrupts cell division (Frumento et al., 2002; Meisel et al., 2011). IDO has also been shown to induce immunomodulatory effects by inhibiting $\mathrm{T}$ cells proliferation and modulating the function of $\mathrm{B}, \mathrm{T}$ cells, and natural killer (NK) cell (Poormasjedi-Meibod et al., 2013).

\section{Indirect Mechanisms}

The antibacterial effects of MSCs can be indirectly mediated by increasing phagocytic activity of macrophages and neutrophils (Hosseiniyan Khatibi et al., 2020). These cells can also induce immunomodulatory effects mentioned in Figure 2 by modulating immune responses and regulating cytokine homeostasis and reducing immune cells transfer into the damaged organ, and thereby provide the conditions for tissue remodeling and healing. Moreover MSC-Exos perform their major immunomodulatory effects by inhibiting $\mathrm{T}$ cell proliferation and converting these cells to Tregs as well as reprogramming M1 macrophages to the M2 phenotype (Riazifar et al., 2019; Hoseini et al., 2020; Hosseiniyan Khatibi et al., 2020; Liu W. et al., 2020). These cells and their exosomes can also inhibit the proliferation and function of $\mathrm{B}$ cells, natural killer cells (NKC), and dendritic cells (DC). MSCs can induce both bacterial clearance and immunomodulatory effects, which are dependent on inflammatory signals in the environment (Fan et al., 2019; Xie et al., 2020). MSCs increase immune responses during the early phases of inflammation such that in addition to the migration of neutrophils to sites of inflammation, MSCs induce lymphocyte and M1 macrophages, through the production of chemokines. In fact, the stimulatory effects of mesenchymal cells on immune cells occur when these cells encounter insufficient levels of proinflammatory cytokines such as TNF and IFN- $\gamma$, while MSCs and MSC-Exos provide conditions for immunosuppressing during exposure to high levels of inflammatory cytokines through polarization to antiinflammatory cells, M2 macrophages, and Tregs (Raicevic et al., 2010; Bernardo and Fibbe, 2013; Song et al., 2017; Xie et al., 2020). Thus, MSCs can activate both phenotypes of macrophages and provide a balance between inflammatory and anti-inflammatory 
TABLE 1 | Antibacterial and Immunomodulatory Effects of MSCs and MSC-Exos in in vitro and in vivo studies.

\begin{tabular}{|c|c|c|c|}
\hline Study type & Source of MSC & Outcomes & References \\
\hline $\begin{array}{l}\text { In vivo: } \\
\text { Murine Cystic fibrosis }\end{array}$ & BM-MSC, AT-MSC & $\begin{array}{l}\uparrow \text { Enhance antibiotic sensitivity } \\
\uparrow \text { Capacity to kill bacteria (Pseudomonas aeruginosa, } \\
\text { Staphylococcus } \\
\text { aureus) } \\
\uparrow \text { LL-37 }\end{array}$ & $\begin{array}{l}\text { Sutton et al., } \\
2017\end{array}$ \\
\hline $\begin{array}{l}\text { In vitro: } \\
\text { Bacterial growth in Equine } \\
\text { model }\end{array}$ & BM-MSC, AT-MSC, EM-MSC & $\begin{array}{l}\downarrow \text { Growth of E. coli } \\
\uparrow \text { Lipocalin-2 expression } \\
\uparrow \text { MCP-1, IL-6, IL-8, and CCL5 }\end{array}$ & $\begin{array}{l}\text { Cortés-Araya } \\
\text { et al., } 2018\end{array}$ \\
\hline $\begin{array}{l}\text { In vitro: } \\
\text { Chronic skin wounds in Equine } \\
\text { model }\end{array}$ & PB-MSC & $\begin{array}{l}\downarrow \text { Growth of E. coli and S. aureus biofilms } \\
\uparrow \text { Cystatin C, elafin, lipocalin, cthelicidin }\end{array}$ & $\begin{array}{l}\text { Harman et al., } \\
2017\end{array}$ \\
\hline $\begin{array}{l}\text { Ex vivo: } \\
\text { Acute Lung Injury in Mice }\end{array}$ & HU-MSC & $\begin{array}{l}\uparrow \text { Keratinocyte growth factor (KGF) } \\
\downarrow \text { Influx of neutrophils } \\
\downarrow \text { Lung protein permeability } \\
\downarrow \text { Pulmonary edema }\end{array}$ & Zhu et al., 2014 \\
\hline $\begin{array}{l}\text { In vivo: } \\
\text { Chronic inflammation } \\
\text { (Staphylococcus aureus) of the } \\
\text { ovaries in mice }\end{array}$ & BM-MSC & $\begin{array}{l}\downarrow \text { Leukocyte infiltration in ovaries } \\
\downarrow \text { Number of atretic follicles } \\
\uparrow \text { Ovary morphological } \\
\text { parameters } \\
\downarrow \text { Apoptotic oocytes } \\
\uparrow \text { Pregnancy rate }\end{array}$ & $\begin{array}{l}\text { Volkova et al., } \\
2017\end{array}$ \\
\hline $\begin{array}{l}\text { In vivo: } \\
\text { Chronic salpingitis (Chlamydia } \\
\text { trachomatis) murine model }\end{array}$ & hUC-MSC & $\begin{array}{l}\downarrow \text { Macrophage infiltration } \\
\uparrow \text { IL-10 } \\
\downarrow \text { FT cell apoptosis (Caspase-3) } \\
\uparrow \text { Pregnancy rate }\end{array}$ & $\begin{array}{l}\text { Liao et al., } \\
2019\end{array}$ \\
\hline $\begin{array}{l}\text { In vitro: } \\
\text { Human Fetal Liver }\end{array}$ & FL-MSC-Exos & $\begin{array}{l}\downarrow \text { Proliferation, activation, and cytotoxicity of NK cells } \\
\text { via TGFb }\end{array}$ & Fan et al., 2019 \\
\hline $\begin{array}{l}\text { In vivo: } \\
\text { Intrauterine adhesions in a } \\
\text { female rat model }\end{array}$ & UC-MSCs-EVs & $\begin{array}{l}\downarrow T N F-\alpha, \\
\downarrow T G F-\beta \\
\downarrow \text { LL-1, } \\
\downarrow \| L-6 \\
\downarrow R \text { RUNX2, } \\
\downarrow \text { Fibrosis } \\
\downarrow \text { collagen-। } \\
\downarrow \text { VEGF } \\
\downarrow \text { IUA }\end{array}$ & $\begin{array}{l}\text { Ebrahim et al., } \\
2018\end{array}$ \\
\hline $\begin{array}{l}\text { In vivo: } \\
\text { Premature ovarian insufficiency } \\
\text { model mice }\end{array}$ & hU-MSC-Exos & $\begin{array}{l}\uparrow \text { Restored ovarian phenotype and function } \\
\uparrow \text { ovarian cells proliferation } \\
\uparrow \text { exosomal miR-17-5P } \\
\downarrow \text { SIRT7 expression }\end{array}$ & $\begin{array}{l}\text { Ding et al., } \\
2020\end{array}$ \\
\hline $\begin{array}{l}\text { In vitro: } \\
\text { inflammation in endometrial } \\
\text { cells of equine models }\end{array}$ & A-MSC- MVs & $\begin{array}{l}\downarrow \text { Apoptosis rate } \\
\downarrow \text { Pro-inflammatory gene expression } \\
\downarrow \text { Pro-inflammatory cytokines secretion }\end{array}$ & $\begin{array}{l}\text { Perrini et al., } \\
2016\end{array}$ \\
\hline
\end{tabular}


TABLE 1 | (Continued)

\begin{tabular}{|c|c|c|c|}
\hline Study type & Source of MSC & Outcomes & References \\
\hline $\begin{array}{l}\text { Ex vivo: } \\
\text { Lung injury models in mice }\end{array}$ & BM-MSC-EV & $\begin{array}{l}\uparrow \mathrm{M} 2 \text { macrophage marker expression } \\
\uparrow \text { Phagocytic macrophage Phenotype } \\
\uparrow \text { Mitochondrial transfer to macrophage } \\
\downarrow \text { Inflammation and lung injury }\end{array}$ & $\begin{array}{l}\text { Morrison et al., } \\
2017\end{array}$ \\
\hline $\begin{array}{l}\text { In vitro: } \\
\text { Asthma in human }\end{array}$ & BM-MSC-Exos & $\begin{array}{l}\text { 个IL-10 } \\
\text { } T \text { TGF- } \beta 1 \\
\text { 个Immunosuppression capacity of Tregs }\end{array}$ & Du et al., 2017 \\
\hline
\end{tabular}

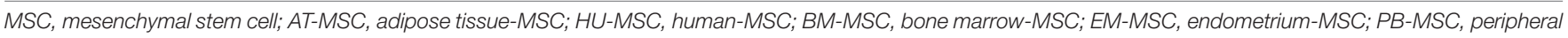

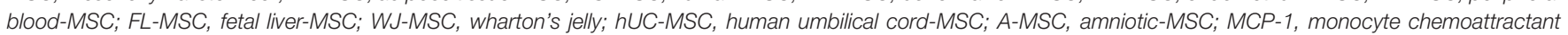
protein-1; CCL5, chemokine ligand-5; FT, Fallopian tube; IUAs, intrauterine adhesions.

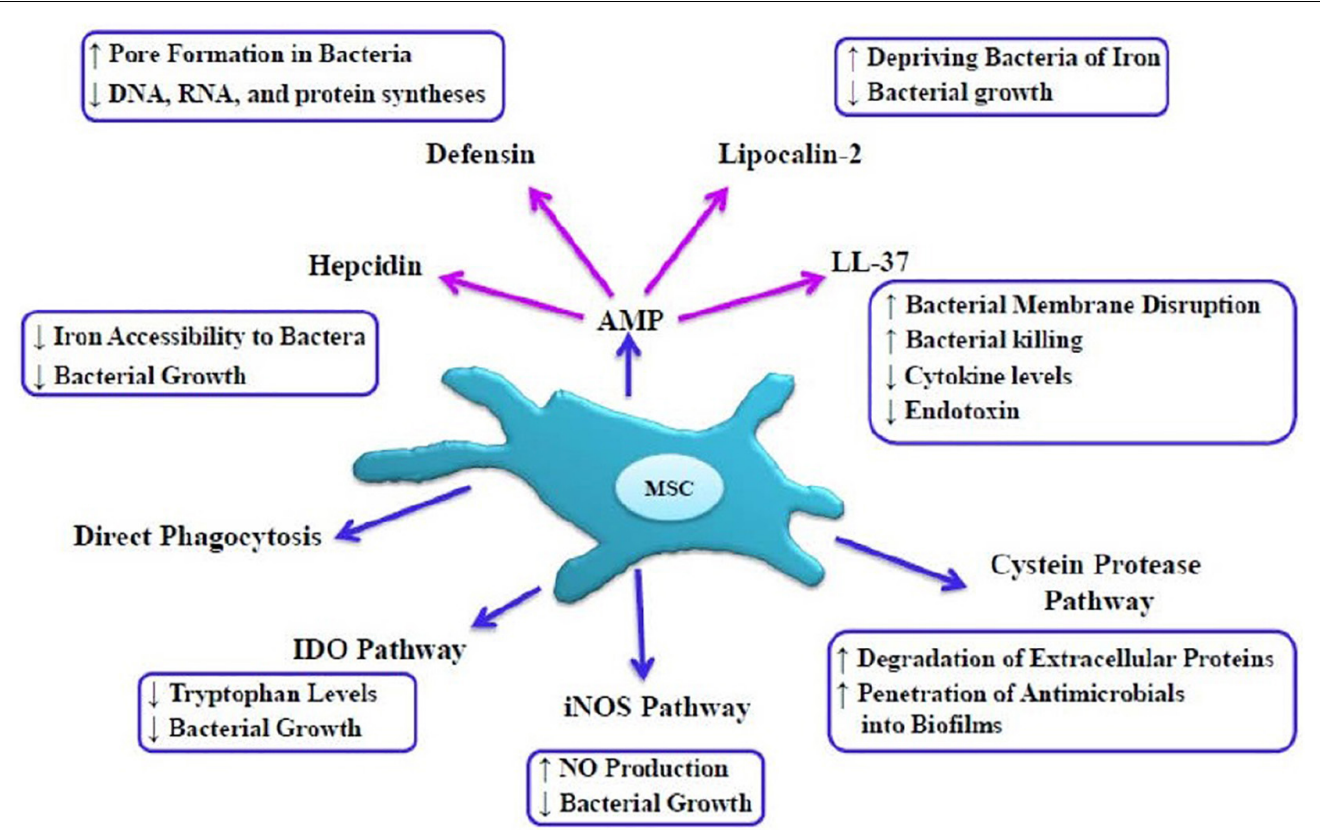

FIGURE 1 | Direct mechanisms of MSC-mediated bacterial killing, MSC exert direct antibacterial effects due to host defense peptides or AMPs. MScs can mediate bacterial killing by disrupting the integrity of the bacterial membrane, creating pores in the bacterial membrane, preventing of iron uptake, inhibiting biofilm formation, depleting tryptophan in microorganisms, and halting the growth of bacteria. IDO pathways, Indoleamine 2,3 dioxygenase; iNOS pathways, inducible nitric oxide synthase; NO, nitric oxide.

responses through interaction with the immune system and thereby provide the condition for maintaining integrity and homeostasis of tissue (Liu W. et al., 2020; Xie et al., 2020). MSCs inhibit proliferation and function of $\mathrm{T}$ cells by secreting factors such as nitric oxide (NO), IDO, prostanglandin-E2 (PGE2), transforming growth factor (TGF)- $\beta$, and interleukin (IL)-10 (DelaRosa and Lombardo, 2010).

$\mathrm{Kol}$ et al. (2014) in the study of effects of adipose-derived MSCs on intestinal microbes (Salmonella typhimurium and Lactobacillus acidophilus) concluded that these cells could increase the expression of key immunomodulatory genes including COX2, IL-6, and IL-8, as well as increase the secretion of PGE2, IL-6, and IL-8, and they also found that exposure of MSCs to $S$. typhimurium increased the capacity of these cells to inhibit $\mathrm{T}$ cell proliferation via PGE2. MSC-Exos also exert their immunomodulatory effects through their RNA and proteins (Lo Sicco et al., 2017). Song et al. stated that exosomal miR-146a is an anti-inflammatory micro-RNA that is transferred into macrophages and leads to polarization to M2 phenotype and ultimately increases survival in sepsis models of mice (Song et al., 2017).

It has also been shown that MSCs inhibit $\mathrm{T}$ cell activity by inhibiting the function, differentiation, and maturation of dendritic cells (DCs) (Aggarwal and Pittenger, 2005). DCs are the main cells of the immune system which present antigens to $\mathrm{T}$ cells and are able to express high levels of co-stimulatory molecules and thereby effectively induce immune responses; thus MSCs and MSC-Exos can lead to inhibition of T cells function and development of Tregs by inducing an inhibitory effect on DCs (Aggarwal and Pittenger, 2005; Jiang et al., 2005). Moreover, MSCs lead to recruitment and stimulation of polymorphonuclear (PMN) cells such as neutrophils, by secreting 


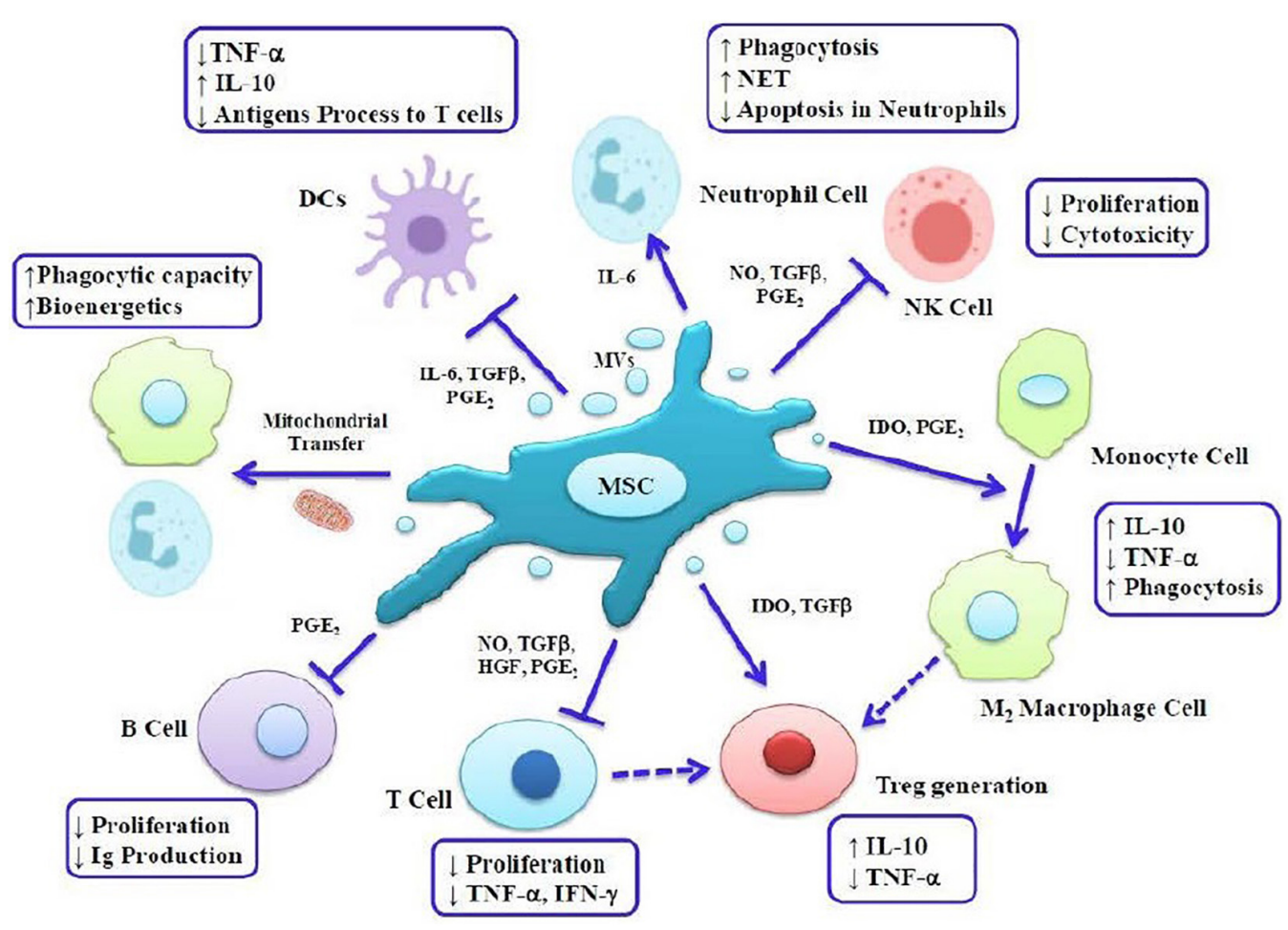

FIGURE 2 | The antibacterial effects of MSC can be indirectly mediated by increasing phagocytic activity of macrophages and neutrophils. These cells can also induce immunomodulatory effects by modulating immune responses and regulating cytokine homeostasis. MVs, microvesicles; DC, dendritic cell; NKC, natural killer cell; NET, neutrophil extracellular trap; IFN, interferon; TNF, tumor necrosis factor; NO, nitric oxide; PGE2, prostaglandin E2; TGF, transforming growth factor; IDO, indoleamine 2,3 dioxygenase; Treg, T regulatory cell; Ig, immunoglobulin.

IL-6 and IL-8 (Brandau et al., 2014). Neutrophils induce the killing of microorganisms by phagocytosis and internalization of them into the phagolysosome, and it has also been shown that these cells, through mechanism of neutrophil extracellular traps (NETs), immobilize microorganisms to prevent their spread in the environment (Hirschfeld, 2014; Jackson et al., 2016). Studies show that MSCs and MSC-Exos not only increase phagocytosis activity of neutrophils but also protect neutrophils from apoptosis (Harrell et al., 2019; Qian et al., 2021). In addition, research showed that direct co-culture of MSCs and their exosomes with macrophages induce mitochondrial transfer from MSCs to macrophages via formation of structures called tunneling nanotubes (TNT) that leads to increase in the phagocytic activity of macrophages and improvement in their bioenergetics (Hirschfeld, 2014; Qian et al., 2021).

\section{PATHOGENESIS OF N. GONORRHOEAE AND C. TRACHOMATIS IN THE FEMALE REPRODUCTIVE TRACT}

Neisseria gonorrhoeae and Chlamydia trachomatis are gramnegative bacteria that are both considered obligate human pathogens, and they are known as the most common cause of sexually transmitted diseases (STDs) (Dehghan Marvast et al., 2016, 2018; Chen et al., 2018; Lenz and Dillard, 2018).
$N$. gonorrhoeae mainly affects the mucous membranes of female reproductive tracts. This infection starts from the lower reproductive tract including the vagina and ectocervix and can spread to the upper female genital tract (endometrium and fallopian tubes) (Lenz and Dillard, 2018). Chlamydia is also an intracellular pathogen that infects the epithelial cells of the endocervix in women and the urethra in men (O'Connell and Ferone, 2016). During its evolutionary cycles, Chlamydia forms structures called elementary bodies (EBs) and reticulate bodies (RBs). EBs are infective forms that are metabolically inactive, but after chlamydia enters the host cell, EBs convert to RBs that are metabolically active but non-infectious and are considered as the replicating form of the bacteria (Brunham and ReyLadino, 2005). N. gonorrhoeae and C. trachomatis infections can be symptomatic or asymptomatic and without treatment lead to complications such as pelvic inflammatory disease (PID), obstruction of FT, tubal scarring, and loss of ciliated cells function in these areas (Dehghan Marvast et al., 2017; Tsevat et al., 2017). Studies have reported that N. gonorrhoeae attach to nonciliated cells through pili and Opa proteins in FT but lead to loss of ciliated cells function and eventually the death of these cells (Edwards and Apicella, 2004; Quillin and Seifert, 2018). Various studies have linked the death of these cells to the presence of toxic factors in bacteria, including lipopolysaccharide (LPS) and lipooligosaccharide (LOS), which induce the host immune system (Gregg et al., 1981; Christodoulides, 2019; 
Gulati et al., 2019). In the gonococcal infections following exposure to pathogen associated molecular patterns (PAMPs), the secretion of cytokine TNF is one of the first responses of the host immune system (Patrone and Stein, 2007). One study reported that increase in the concentration of TNF was associated with decrease in function of ciliated cells (McGee et al., 1999). On the other hand, studies have reported that the reduction in ciliated cell activity and death of these cells during gonococcal infections has been attributed to the induction of apoptosis in FT epithelial cell by the TNF cytokine (Edwards and Apicella, 2004; Morales et al., 2006). Evidences also are showed that other factors, including IL1, IL-6, IL-8, monocyte chemoattractant protein-1 (MCP-1), and granulocyte macrophage colony-stimulating factor (GMCSF) secreted during gonococal infections (Maisey et al., 2003; Velasquez et al., 2012). Moreover, one study reported that the levels of cytokines IL-2 and IL-12 were rapidly upregulated during exposure to $N$. gonorrhoeae infection, such that IL-2 was associated with lymphocyte proliferation, while IL-12 increased IFN $\gamma$ production by lymphocytes and NKC (Rarick et al., 2006). Although magnitude Th17 responses in gonococcal infections lead to the release of IL-17 and the recruitment of neutrophils, the relative resistance of $N$. gonorrhoeae to neutrophil function and the lack of an effective response to pathogen clearance have been reported (Witt et al., 1976; Liu et al., 2012). Moreover, immune responses in $C$. trachomatis infection include activation of Th1 and proinflammatory cytokines IL-2, IL-6, TNF, and INF$\gamma$ (Arno et al., 1990). One study reported that INF- $\gamma$ levels in endocervical secretions of women with $\mathrm{C}$. trachomatis infection were five times higher than uninfected women (Sellami et al., 2014). Also, studies show that TLR-2 and TLR-4, which are increased in C. trachomatis infection, play an important role in inducing innate and acquired immune responses (Agrawal et al., 2011; Lovett and Duncan, 2019).

But although lymphocyte proliferative responses in gonococcal infections are increased compared to healthy individuals, these immune responses cannot provide strong protection against recurrence of the infection (Zhu et al., 2012). Moreover, $N$. gonorrhoeae are able to manipulate and effect the function of host immune cells, so that gonococcal infections have been shown to exert immunosuppressive signaling by inhibiting the proliferation of DCs, T cells, and B cell (Manicassamy et al., 2009; Escobar et al., 2018). On the other hand, N. gonorrhoeae induces the expression of immunosuppressive cytokines such as TGF- $\beta$ and IL-10 so that it has been stated that $N$. gonorrhoea suppresses the activity of Th1 and Th2 by inducing the expression of TGF- $\beta$ (Mascellino et al., 2011).

Evidence suggests that the immune responses generated during the pathogenesis of Neisseria and Chlamydia are polarized toward cytotoxic responses and provide the conditions for obstruction and scaring in FT (Menon et al., 2015; Jefferson et al., 2021). According to research, different mechanisms are involved in inducing infertility following $N$. gonorrhoeae and C. trachomatis infection. The first mechanism involves the ascension of the infection to the upper reproductive tract (Hafner, 2015). The second mechanism involves the persistence of the infection, which leads to long-term pathological immune responses and thus provides the conditions for damage to the epithelial cells of FT (Batteiger et al., 2010). It has also been suggested that treatment failures by antibiotics lead to recurrence of the infection and the development of infertility via persistence of infection (Menon et al., 2015). The third mechanism involves the secretion of cytokines from pathogeninfected epithelial cells, which induce proinflammatory immune responses that lead to severe epithelial cell damage and fibrosis or scarring following repair mechanisms by infiltrating fibroblasts (Darville, 2021). Since that salpingitis induced by $N$. gonorrhoeae and C. trachomatis infections leads to pathological immune responses and induces infertility, it is necessary to create a good balance between immune activation and immune suppression.

\section{THERAPEUTIC POTENTIAL OF MESENCHYMAL STEM CELL-DERIVED EXOSOMES ON SALPINGITIS INDUCED BY N. GONORRHOEAE AND C. TRACHOMATIS INFECTIONS}

Due to the unique life cycles of $N$. gonorrhoeae and C. trachomatis, the major PID caused by these infections are chronic, so antibiotic therapy is less effective, which often leads to persistence of the infection and reinfection (Chen et al., 2020). Various studies listed in Table 1 have reported the positive effects of MSC-Exos in the treatment of gynecological diseases (Sun et al., 2019; Zhang et al., 2019; Liu C. et al., 2020; Xin et al., 2020; Zhao et al., 2020; Lee et al., 2021; Liao et al., 2021). Today, MSC-Exos are used in cell therapy, regenerative medicine, autoimmune, and microbial disease due to their unique properties such as high proliferative capacity, easy isolation, and secretion of bioactive factors, as well as having anti-apoptotic, antimicrobial, antiscarring, tissue repair, and wound healing effects (Ha et al., 2020; Raghav et al., 2021).

\section{Exosomes Isolation of Mesenchymal Stem Cell}

Various techniques are used to separate exosomes from MSCs, including ultracentrifugation, ultrafiltration, precipitation, immunological separation, chromatography, and nanoFACS (Théry et al., 2018; Rezaie et al., 2021). However, each of these methods has advantages and disadvantages, and studies have reported that the ultracentrifugation method is the most common standard method for isolating exosomes (MomenHeravi et al., 2013). But Klymiuk et al. (2019) in their study stated that the ultrafiltration method had higher results and efficiencies in size-based isolation compared to the ultracentrifugation method, and a 50-fold increase in concentration and less time for isolation compared to the ultracentrifugation method was reported. On the other hand, due to several overlapping features between exosomes and viruses such as size, shape, density, and biogenesis, Rezaie et al. (2021) reported that nanoFACS and immunological methods are more suitable for isolating exosomes from viruses in infected samples. 
Moreover, in most studies it has been stated that in order to achieve better specificity and recovery in the separation of $\mathrm{EV}$ or EV subtypes, the use of a combination of techniques or additional techniques is recommended (Nikfarjam et al., 2020; Liangsupree et al., 2021).

\section{Advantages and Limitations of Mesenchymal Stem Cells-Derived Exosomes Application}

Various studies have shown the superiority of using exosomes rather than MSCs. The risk of tumor formation has not been reported in exosome-based therapies, while the tumorigenic risk in MSC-based therapies has been observed in several studies (Mendt et al., 2019; Wei et al., 2021). In addition to the fact that lower side effects of exosomal therapy than mesenchymal transplantation have been reported in various studies, Sun et al. (2015) have reported increased expression of HLA and immunological rejection in MSCs transplantation. In addition, studies have shown that exosomes are not affected by apoptotic processes and cell death due to their noncellular nature, and therefore their stability is greater in the damaged area (Lou et al., 2017; Wang et al., 2021). Exosomes are also less expensive to produce than MSCs and are more stable to store and easier for storage and, recently, it has received more attention than cell-based therapy due to the ability of exosomes to transport therapeutic biomolecules and facilitate repair of the damaged site (Babaei and Rezaie, 2021). Despite the advantages of exosome therapy and its therapeutic potential compared to their parent cells, several disadvantages have been reported, including the lack of renewal potential, the loss of some paracrine factors during the use of isolation methods, and the possibility of viral infections transmission and short half-life of exosomes (Takahashi et al., 2013; Babaei and Rezaie, 2021).

\section{Application Studies of Mesenchymal Stem Cell-Derived Exosomes}

Different evidences mentioned in Table $\mathbf{1}$ have reported the antimicrobial effects of MSCs and MSC-Exos. However, these studies are more limited to animal studies and clinical dates are low. In the evaluation of antimicrobial activity of MSCs in chronic infections associated with biofilm formation, it has been reported that co-administration of MSCs with antibiotics affected both direct and indirect pathways of these cells, such that secretion factors of MSCs inhibited biofilm formation and disrupted the growth of stabilized biofilms (Johnson et al., 2017). It has also been suggested that administration of these cells with antibiotics can have a synergistic effect in reducing a variety of multi-drug resistance (MDR) in bacterial infections (Chow et al., 2020; Russell et al., 2020). Liao et al. reported that hUC-MSC reduced hydrosalpinx, macrophage infiltration, and the expression of IL-10 in the oviduct. Also, they observed that hUC-MSC induced anti-apoptotic effects by reducing the expression level of caspase-3. In addition, it was reported that pregnancy rate increased significantly, and these effects were attributed to the anti-inflammatory and anti-apoptotic properties of hUC-MSC (Liao et al., 2019). In addition, Li et al. (2017) observed that WJ-MSCs restored the epithelial structure of the FT and concentration of TNF was decreased significantly in the treatment group with WJ-MSCs, and they also reported that WJ-MSCs improved the secretion of oviduct glycoprotein and fertility partially in rabbits with chronic salpingitis. Furthermore, Ebrahim et al. (2018) revealed that hUC-MSC-EV alone or in combination with estrogen significantly reduced intrauterine adhesions in female rats due to decrease in inflammatory cytokines (TNF- $\alpha$, IL-1, IL-6) and fibrotic markers (RUNX2, TGF- $\beta$, collagen-I). Also, Ding et al. reported that hUMSC-Exos due to microRNA-17-5P repaired the phenotype and function of the ovary, elevated ovarian cells proliferation, and decreased ROS accumulation in POI mouse model (Ding et al., 2020).

\section{CONCLUSION}

Experimental studies show that MSCs and MSC-Exos have a high potential for the treatment of inflammatory and microbial diseases. Furthermore, MSC-Exos have similar abilities to their parent cells, which have a high potential for modulating immune responses due to their therapeutic biomolecules. However, the priority of using MSC-Exos compared to cell-based therapy in terms of safety and stability has been reported in several studies. In addition, MSC-Exos induce the phagocytic activity of neutrophils and macrophages and improve the bioenergetics of them to provide the conditions for increasing the survival of these cells and the continuity of their function in bacterial phagocytes. On the other hand, MSC-Exos play an important role in preventing the pathological immune response by interacting with immune cells and reprogramming M1 macrophages to the M2 phenotype and converting Th to Tregs. Therefore, it can be said that MSC-Exos due to these properties can inhibit pathological immune responses during $N$. gonorrhoeae and C. trachomatis infections, and in this way MSC-Exos provide the conditions for tissue repair and prevent severe tissue damage during infection.

\section{AUTHOR CONTRIBUTIONS}

MZ wrote the draft of manuscript. LD, MI, and SM revised the parts of Infectious and infertility. BA read the manuscript and did the final revision and agreed with the final version of the manuscript.

\section{FUNDING}

This work was funded by Stem Cell Biology Research Center.

\section{ACKNOWLEDGMENTS}

The authors thank Dr. Ali Mohammad Abdoli, the manager of the Yazd Reproductive Sciences Institute. 


\section{REFERENCES}

Adib, M., Seifati, S. M., Ashkezari, M. D., Khoradmehr, A., Rezaee-Ranjbar-Sardari, R., Tahajjodi, S. S., et al. (2020a). The effect of the human cumulus cellsconditioned medium on in vitro maturation of mouse oocyte: an experimental study. Int. J. Reprod. Biomed. 18, 1019-1028. doi: 10.18502/ijrm.v18i12.8023

Adib, M., Seifati, S. M., Dehghani Ashkezari, M., Akyash, F., Khoradmehr, A., and Aflatoonian, B. (2020b). Effect of human testicular cells conditioned medium on in vitro maturation and morphology of mouse oocytes. Int. J. Fertil. Steril. 14, 175-184. doi: 10.22074/ijfs.2020.6097

Aggarwal, S., and Pittenger, M. F. (2005). Human mesenchymal stem cells modulate allogeneic immune cell responses. Blood 105, 1815-1822. doi: 10. 1182/blood-2004-04-1559

Agrawal, T., Bhengraj, A. R., Vats, V., Salhan, S., and Mittal, A. (2011). Expression of TLR 2, TLR 4 and iNOS in cervical monocytes of Chlamydia trachomatisinfected women and their role in host immune response. Am. J. Reprod. Immunol. 66, 534-543. doi: 10.1111/j.1600-0897.2011.01064.x

Akbari, A., and Rezaie, J. (2020). Potential therapeutic application of mesenchymal stem cell-derived exosomes in SARS-CoV-2 pneumonia. Stem Cell Res. Ther 11:356. doi: 10.1186/s13287-020-01866-6

Akyash, F., Javidpou, M., Nodoushan, F. S., and Aflatoonian, B. (2016a). Human embryonic stem cells derived mesenchymal stem/stromal cells and their use in regenerative medicine. J. Stem Cell Res. Ther. 1, 272-274. doi: 10.15406/jsrt. 2016.01.00047

Akyash, F., Sadeghian-Nodoushan, F., and Aflatoonian, B. (2016b). Isolation, Culture and Characterization of Human Endometrial Mesenchymal Stem/Stromal Cells (EnMSCs): a mini review. Austin J. In Vitro Fertili. 3:1025.

Akyash, F., Javidpou, M., Yazd, E. F., Golzadeh, J., Hajizadeh-Tafti, F., Aflatoonian, R., et al. (2020). Characteristics of the human endometrial regeneration cells as a potential source for future stem cell-based therapies: a lab resources study. Int. J. Reprod. Biomed. 18, 943-950. doi: 10.18502/ijrm.v13i11.7961

Alcayaga-Miranda, F., Cuenca, J., and Khoury, M. (2017). Antimicrobial activity of mesenchymal stem cells: current status and new perspectives of antimicrobial peptide-based therapies. Front. Immunol. 8:339. doi: 10.3389/fimmu.00339

Arabpour, M., Saghazadeh, A., and Rezaei, N. (2021). Anti-inflammatory and M2 macrophage polarization-promoting effect of mesenchymal stem cellderived exosomes. Int. Immunopharmacol. 97:107823. doi: 10.1016/j.intimp. 2021.107823

Arno, J. N., Ricker, V. A., Batteiger, B. E., Katz, B. P., Caine, V. A., and Jones, R. B. (1990). Interferon-gamma in endocervical secretions of women infected with Chlamydia trachomatis. J. Infect. Dis. 162, 1385-1389. doi: 10.1093/infdis/162. 6.1385

Babaei, M., and Rezaie, J. (2021). Application of stem cell-derived exosomes in ischemic diseases: opportunity and limitations. J. Transl. Med. 19:196. doi: 10.1186/s12967-021-02863-w

Batteiger, B. E., Tu, W., Ofner, S., Van Der Pol, B., Stothard, D. R., Orr, D. P., et al. (2010). Repeated Chlamydia trachomatis genital infections in adolescent women. J. Infect. Dis. 201, 42-51. doi: 10.1086/648734

Bernardo, M. E., and Fibbe, W. E. (2013). Mesenchymal stromal cells: sensors and switchers of inflammation. Cell Stem Cell 13, 392-402. doi: 10.1016/j.stem.2013. 09.006

Bogdan, C. (2015). Nitric oxide synthase in innate and adaptive immunity: an update. Trends Immunol. 36, 161-178. doi: 10.1016/j.it.2015.01.003

Brandau, S., Jakob, M., Bruderek, K., Bootz, F., Giebel, B., Radtke, S., et al. (2014). Mesenchymal stem cells augment the anti-bacterial activity of neutrophil granulocytes. PLoS One 9:e106903. doi: 10.1371/journal.pone.0106903

Brogden, K. A. (2005). Antimicrobial peptides: pore formers or metabolic inhibitors in bacteria? Nat. Rev. Microbiol. 3, 238-250. doi: 10.1038/ nrmicro1098

Brunham, R., and Rey-Ladino, J. (2005). Immunology of Chlamydia infection: implications for a Chlamydia trachomatis vaccine. Nat. Rev. Immunol. 5, 149161. doi: $10.1038 /$ nri1551

Burlacu, A., Grigorescu, G., Rosca, A. M., Preda, M. B., and Simionescu, M. (2013). Factors secreted by mesenchymal stem cells and endothelial progenitor cells have complementary effects on angiogenesis in vitro. Stem Cells Dev. 22, 643-653. doi: $10.1089 / \mathrm{scd} .2012 .0273$
Chen, S., Wang, Y., Liao, L., Meng, L., Li, J., Shi, C., et al. (2020). Similar repair effects of human placenta, bone marrow mesenchymal stem cells, and their exosomes for damaged SVOG Ovarian Granulosa Cells. Stem Cells Int. 2020:8861557. doi: 10.1155/2020/8861557

Chen, Y., Premasiri, W. R., and Ziegler, L. D. (2018). Surface enhanced Raman spectroscopy of Chlamydia trachomatis and Neisseria gonorrhoeae for diagnostics, and extra-cellular metabolomics and biochemical monitoring. Sci. Rep. 8:5163. doi: 10.1038/s41598-018-23562-5

Chow, L., Johnson, V., Impastato, R., Coy, J., Strumpf, A., and Dow, S. (2020). Antibacterial activity of human mesenchymal stem cells mediated directly by constitutively secreted factors and indirectly by activation of innate immune effector cells. Stem Cells Transl. Med. 2, 235-249. doi: 10.1002/sctm.19-0092

Christodoulides, M. (2019). Preparation of Lipooligosaccharide (LOS) from Neisseria gonorrhoeae. Methods Mol. Biol. 1997, 87-96. doi: 10.1007/978-14939-9496-0_6

Cortés-Araya, Y., Amilon, K., Rink, B. E., Black, G., Lisowski, Z., Donadeu, F. X., et al. (2018). Comparison of antibacterial and immunological properties of mesenchymal stem/stromal cells from equine bone marrow, endometrium, and adipose tissue. Stem Cells Dev. 27, 1518-1525. doi: 10.1089/scd.2017.0241

Croitoru-Lamoury, J., Lamoury, F. M., Caristo, M., Suzuki, K., Walker, D., Takikawa, O., et al. (2011). Interferon- $\gamma$ regulates the proliferation and differentiation of mesenchymal stem cells via activation of indoleamine 2,3 dioxygenase (IDO). PLoS One 6:e14698. doi: 10.1371/journal.pone.0014698

Dahl, S. L., Woodworth, J. S., Lerche, C. J., Cramer, E. P., Nielsen, P. R., Moser, C., et al. (2018). Lipocalin-2 functions as inhibitor of innate resistance to Mycobacterium tuberculosis. Front. Immunol. 9:2717. doi: 10.3389/fimmu.2018. 02717

Darville, T. (2021). Pelvic inflammatory disease due to Neisseria gonorrhoeae and Chlamydia trachomatis: immune evasion mechanisms and pathogenic disease pathways. J. Infect. Dis. 224, 39-46. doi: 10.1093/infdis/jiab031

Däubener, W., Schmidt, S. K., Heseler, K., Spekker, K. H., and MacKenzie, C. R. (2009). Antimicrobial and immunoregulatory effector mechanisms in human endothelial cells. Indoleamine 2,3-dioxygenase versus inducible nitric oxide synthase. Thromb. Haemost. 102, 1110-1116. doi: 10.1160/TH09-04-0250

Dehghan Marvast, L., Aflatoonian, A., Talebi, A. R., Eley, A., and Pacey, A. A. (2017). Relationship between Chlamydia trachomatis and Mycoplasma genitalium infection and pregnancy rate and outcome in Iranian infertile couples. Andrologia 49:e12747. doi: 10.1111/and.12747

Dehghan Marvast, L., Aflatoonian, A., Talebi, A. R., Ghasemzadeh, J., and Pacey, A. A. (2016). Semen inflammatory markers and Chlamydia trachomatis infection in male partners of infertile couples. Andrologia 48, 729-736. doi: 10.1111/and.12501

Dehghan Marvast, L., Talebi, A. R., Ghasemzadeh, J., Hosseini, A., and Pacey, A. A. (2018). Effects of Chlamydia trachomatis infection on sperm chromatin condensation and DNA integrity. Andrologia 50:e12918. doi: 10.1111/and. 12918

DelaRosa, O., and Lombardo, E. (2010). Modulation of adult mesenchymal stem cells activity by toll-like receptors: implications on therapeutic potential. Mediators Inflamm. 2010:865601. doi: 10.1155/2010/865601

Diamond, G., Beckloff, N., Weinberg, A., and Kisich, K. O. (2009). The roles of antimicrobial peptides in innate host defense. Curr. Pharm. Des. 15, 2377-2392. doi: $10.2174 / 138161209788682325$

Ding, C., Zhu, L., Shen, H., Lu, J., Zou, Q., Huang, C., et al. (2020). Exosomal miRNA-17-5p derived from human umbilical cord mesenchymal stem cells improves ovarian function in premature ovarian insufficiency by regulating SIRT7. Stem Cells 38, 1137-1148. doi: 10.1002/stem.3204

Du, Y. M., Zhuansun, Y. X., Chen, R., Lin, L., Lin, Y., and Li, J. G. (2017). Mesenchymal stem cell exosomes promote immunosuppression of regulatory $\mathrm{T}$ cells in asthma. Exp. Cell Res. 363, 114-120. doi: 10.1016/j.yexcr.2017.12.021

Ebrahim, N., Mostafa, O., El Dosoky, R. E., Ahmed, I. A., Saad, A. S., Mostafa, A., et al. (2018). Human mesenchymal stem cell-derived extracellular vesicles/estrogen combined therapy safely ameliorates experimentally induced intrauterine adhesions in a female rat model. Stem Cell Res. Ther. 9:175. doi: 10.1186/s13287-018-0924-z

Edwards, J. L., and Apicella, M. A. (2004). The molecular mechanisms used by Neisseria gonorrhoeae to initiate infection differ between men and women. Clin. Microbiol. Rev. 17, 965-981. doi: 10.1128/CMR.17.4.965-981.2004 
Escobar, A., Rodas, P. I., and Acuña-Castillo, C. (2018). Macrophage-Neisseria gonorrhoeae interactions: a better understanding of pathogen mechanisms of immunomodulation. Front. Immunol. 9:3044. doi: 10.3389/fimmu.2018.03044

Esfandiyari, R., Halabian, R., Behzadi, E., Sedighian, H., Jafari, R., and Imani Fooladi, A. A. (2019). Performance evaluation of antimicrobial peptide ll-37 and hepcidin and $\beta$-defensin- 2 secreted by mesenchymal stem cells. Heliyon 5:e02652. doi: 10.1016/j.heliyon.2019.e02652

Fan, Y., Herr, F., Vernochet, A., Mennesson, B., Oberlin, E., and Durrbach, A. (2019). Human fetal liver mesenchymal stem cell-derived exosomes impair natural killer cell function. Stem Cells Dev. 28, 44-55. doi: 10.1089/scd.2018. 0015

Flo, T. H., Smith, K. D., Sato, S., Rodriguez, D. J., Holmes, M. A., Strong, R. K., et al. (2004). Lipocalin 2 mediates an innate immune response to bacterial infection by sequestrating iron. Nature 432, 917-921. doi: 10.1038/nature03104

Frumento, G., Rotondo, R., Tonetti, M., Damonte, G., Benatti, U., and Ferrara, G. B. (2002). Tryptophan-derived catabolites are responsible for inhibition of $\mathrm{T}$ and natural killer cell proliferation induced by indoleamine 2,3-dioxygenase. J. Exp. Med. 196, 459-468. doi: 10.1084/jem.20020121

Ganz, T., and Nemeth, E. (2012). Hepcidin and iron homeostasis. Biochim. Biophys. Acta 1823, 1434-1443. doi: 10.1016/j.bbamcr.2012.01.014

Goetz, D. H., Holmes, M. A., Borregaard, N., Bluhm, M. E., Raymond, K. N., and Strong, R. K. (2002). The neutrophil lipocalin NGAL is a bacteriostatic agent that interferes with siderophore-mediated iron acquisition. Mol. Cell 10, 1033-1043. doi: 10.1016/s1097-2765(02)00708-6

Gregg, C. R., Melly, M., Hellerqvist, C. G., Coniglio, J. G., and McGee, Z. A. (1981). Toxic activity of purified lipopolysaccharide of Neisseria gonorrhoeae for human fallopian tube mucosa. J. Infect. Dis. 143, 432-439. doi: 10.1093/infdis/143.3.432

Gulati, S., Shaughnessy, J., Ram, S., and Rice, P. A. (2019). Targeting Lipooligosaccharide (LOS) for a Gonococcal Vaccine. Front. Immunol. 10:321. doi: 10.3389/fimmu.2019.00321

Gurunathan, S., Kang, M. H., Jeyaraj, M., Qasim, M., and Kim, J. H. (2019). Review of the isolation, characterization, biological function, and multifarious therapeutic approaches of exosomes. Cells 8:407. doi: 10.3390/cells8040307

Ha, D. H., Kim, H. K., Lee, J., Kwon, H. H., Park, G. H., Yang, S. H., et al. (2020). Mesenchymal stem/stromal cell-derived exosomes for immunomodulatory therapeutics and skin regeneration. Cells 9:1157. doi: 10.3390/cells9051157

Hafner, L. M. (2015). Pathogenesis of fallopian tube damage caused by Chlamydia trachomatis infections. Contraception 92, 108-115. doi: 10.1016/j.contraception. 2015.01.004

Harder, J., and Schröder, J. M. (2005). Psoriatic scales: a promising source for the isolation of human skin-derived antimicrobial proteins. J. Leukoc. Biol. 77, 476-486. doi: 10.1189/jlb.0704409

Harman, R. M., Yang, S., He, M. K., and Van de Walle, G. R. (2017). Antimicrobial peptides secreted by equine mesenchymal stromal cells inhibit the growth of bacteria commonly found in skin wounds. Stem Cell Res. Ther. 8:157. doi: 10.1186/s13287-017-0610-6

Harrell, C. R., Jovicic, N., Djonov, V., Arsenijevic, N., and Volarevic, V. (2019). Mesenchymal stem cell-derived exosomes and other extracellular vesicles as new remedies in the therapy of inflammatory diseases. Cells 8:1605. doi: 10 . $3390 /$ cells 8121605

Hirschfeld, J. (2014). Dynamic interactions of neutrophils and biofilms. J. Oral Microbiol. 6:26102. doi: 10.3402/jom.v6.26102

Hoseini, S. M., Sheikhha, M. H., Kalantar, S. M., Matin, M. M., Aflatoonian, B., Bahrami, A. R., et al. (2020). A comparative analysis of immunomodulatory genes in two clonal subpopulations of $\mathrm{CD} 90+$ amniocytes isolated from human amniotic fluid. Placenta 101, 234-241. doi: 10.1016/j.placenta.2020.10.001

Hosseiniyan Khatibi, S. M., Kheyrolahzadeh, K., Barzegari, A., Rahbar Saadat, Y., and Zununi Vahed, S. (2020). Medicinal signaling cells: a potential antimicrobial drug store. J. Cell. Physiol. 235, 7731-7746. doi: 10.1002/jcp.29728

Jackson, M. V., Morrison, T. J., Doherty, D. F., McAuley, D. F., Matthay, M. A., Kissenpfennig, A., et al. (2016). Mitochondrial transfer via tunneling nanotubes is an important mechanism by which mesenchymal stem cells enhance macrophage phagocytosis in the in vitro and in vivo models of ARDS. Stem Cells 34, 2210-2223. doi: 10.1002/stem.2372

Javidpou, M., Seifati, S. M., Farashahi-Yazd, E., Hajizadeh-Tafti, F., Golzadeh, J., Akyash, F., et al. (2021). Mesenchymal stem/stromal-like cells from diploid and triploid human embryonic stem cells display different gene expression profiles. Iran. Biomed. J. 25, 99-105. doi: 10.29252/ibj.25.2.99
Jefferson, A., Smith, A., Fasinu, P. S., and Thompson, D. K. (2021). Sexually transmitted Neisseria gonorrhoeae infections-update on drug treatment and vaccine development. Medicines 8:11. doi: 10.3390/medicines8020011

Jiang, X. X., Zhang, Y., Liu, B., Zhang, S. X., Wu, Y., Yu, X. D., et al. (2005). Human mesenchymal stem cells inhibit differentiation and function of monocytederived dendritic cells. Blood 105, 4120-4126. doi: 10.1182/blood-2004-020586

Johnson, V., Webb, T., Norman, A., Coy, J., Kurihara, J., Regan, D., et al. (2017). Activated mesenchymal stem cells interact with antibiotics and host innate immune responses to control chronic bacterial infections. Sci. Rep. 7:9575. doi: 10.1038/s41598-017-08311-4

Klymiuk, M. C., Balz, N., Elashry, M. I., Heimann, M., Wenisch, S., and Arnhold, S. (2019). Exosomes isolation and identification from equine mesenchymal stem cells. BMC Vet. Res. 15:42. doi: 10.1186/s12917-019-1789-9

Kol, A., Foutouhi, S., Walker, N. J., Kong, N. T., Weimer, B. C., and Borjesson, D. L. (2014). Gastrointestinal microbes interact with canine adipose-derived mesenchymal stem cells in vitro and enhance immunomodulatory functions. Stem Cells Dev. 23, 1831-1843. doi: 10.1089/scd.2014.0128

Koniusz, S., Andrzejewska, A., Muraca, M., Srivastava, A. K., Janowski, M., and Lukomska, B. (2016). Extracellular vesicles in physiology, pathology, and therapy of the immune and central nervous system, with focus on extracellular vesicles derived from mesenchymal stem cells as therapeutic tools. Front. Cell. Neurosci. 10:109. doi: 10.3389/fncel.2016.00109

Kowal, J., Tkach, M., and Théry, C. (2014). Biogenesis and secretion of exosomes. Curr. Opin. Cell Biol. 29, 116-125. doi: 10.1016/j.ceb.2014.05.004

Krasnodembskaya, A., Song, Y., Fang, X., Gupta, N., Serikov, V., Lee, J. W., et al. (2010). Antibacterial effect of human mesenchymal stem cells is mediated in part from secretion of the antimicrobial peptide LL-37. Stem Cells 28, 2229-2238. doi: 10.1002/stem.544

Kulaksiz, H., Gehrke, S. G., Janetzko, A., Rost, D., Bruckner, T., Kallinowski, B., et al. (2004). Pro-hepcidin: expression and cell specific localisation in the liver and its regulation in hereditary haemochromatosis, chronic renal insufficiency, and renal anaemia. Gut 53, 735-743. doi: 10.1136/gut.2003.022863

Kulaksiz, H., Theilig, F., Bachmann, S., Gehrke, S. G., Rost, D., Janetzko, A., et al. (2005). The iron-regulatory peptide hormone hepcidin: expression and cellular localization in the mammalian kidney. J. Endocrinol. 184, 361-370. doi: $10.1677 /$ joe. 1.05729

Laverty, G., Gorman, S. P., and Gilmore, B. F. (2011). The potential of antimicrobial peptides as biocides. Int. J. Mol. Sci. 12, 6566-6596. doi: 10.3390/ijms 12106566

Lee, B. C., Kang, I., and Yu, K. R. (2021). Therapeutic features and updated clinical trials of mesenchymal stem cell (MSC)-derived exosomes. J. Clin. Med. 10:711. doi: $10.3390 / \mathrm{jcm} 10040711$

Lenz, J. D., and Dillard, J. P. (2018). Pathogenesis of Neisseria gonorrhoeae and the host defense in ascending infections of human fallopian tube. Front. Immunol. 9:2710. doi: 10.3389/fimmu.2018.02710

Li, Z., Zhang, Z., Chen, X., Zhou, J., and Xiao, X. M. (2017). Treatment evaluation of Wharton's jelly-derived mesenchymal stem cells using a chronic salpingitis model: an animal experiment. Stem Cell Res. Ther. 8:232. doi: 10.1186/s13287017-0685-0

Liangsupree, T., Multia, E., and Riekkola, M. L. (2021). Modern isolation and separation techniques for extracellular vesicles. J. Chromatogr. A 1636:461773. doi: 10.1016/j.chroma.2020.461773

Liao, W., Tang, X., Li, X., and Li, T. (2019). Therapeutic effect of human umbilical cord mesenchymal stem cells on tubal factor infertility using a chronic salpingitis murine model. Arch. Gynecol. Obstet. 300, 421-429. doi: 10.1007/ s00404-019-05209-6

Liao, Z., Liu, C., Wang, L., Sui, C., and Zhang, H. (2021). Therapeutic role of mesenchymal stem cell-derived extracellular vesicles in female reproductive diseases. Front. Endocrinol. 12:665645. doi: 10.3389/fendo.2021.66 5645

Liu, C., Yin, H., Jiang, H., Du, X., Wang, C., Liu, Y., et al. (2020). Extracellular vesicles derived from mesenchymal stem cells recover fertility of premature ovarian insufficiency mice and the effects on their offspring. Cell Transplant. 29:963689720923575. doi: 10.1177/0963689720923575

Liu, W., Yu, M., Xie, D., Wang, L., Ye, C., Zhu, Q., et al. (2020). Melatoninstimulated MSC-derived exosomes improve diabetic wound healing through regulating macrophage M1 and M2 polarization by targeting the PTEN/AKT pathway. Stem Cell Res. Ther. 11:259. doi: 10.1186/s13287-020-01756-x 
Liu, Y., Islam, E. A., Jarvis, G. A., Gray-Owen, S. D., and Russell, M. W. (2012). Neisseria gonorrhoeae selectively suppresses the development of Th1 and Th2 cells, and enhances Th17 cell responses, through TGF-beta-dependent mechanisms. Mucosal Immunol. 5, 320-331. doi: 10.1038/mi.2012.12

Lo Sicco, C., Reverberi, D., Balbi, C., Ulivi, V., Principi, E., Pascucci, L., et al. (2017). Mesenchymal stem cell-derived extracellular vesicles as mediators of anti-inflammatory effects: endorsement of macrophage Polarization. Stem Cells Transl. Med. 6, 1018-1028. doi: 10.1002/sctm.16-0363

Lou, G., Chen, Z., Zheng, M., and Liu, Y. (2017). Mesenchymal stem cell-derived exosomes as a new therapeutic strategy for liver diseases. Exp. Mol. Med. 49:e346. doi: 10.1038/emm.2017.63

Lovett, A., and Duncan, J. A. (2019). Human immune responses and the natural history of Neisseria gonorrhoeae infection. Front. Immunol. 19:3187. doi: 10. 3389/fimmu.2018.03187

Maisetta, G., Petruzzelli, R., Brancatisano, F. L., Esin, S., Vitali, A., Campa, M., et al. (2010). Antimicrobial activity of human hepcidin 20 and 25 against clinically relevant bacterial strains: effect of copper and acidic pH. Peptides 31, 1995-2002. doi: 10.1016/j.peptides.2010.08.007

Maisey, K., Nardocci, G., Imarai, M., Cardenas, H., Rios, M., Croxatto, H. B., et al. (2003). Expression of proinflammatory cytokines and receptors by human fallopian tubes in organ culture following challenge with Neisseria gonorrhoeae. Infect. Immun. 71, 527-532. doi: 10.1128/IAI.71.1.527-532

Manicassamy, S., Ravindran, R., Deng, J., Oluoch, H., Denning, T. L., Kasturi, S. P., et al. (2009). Toll-like receptor 2-dependent induction of vitamin A-metabolizing enzymes in dendritic cells promotes $\mathrm{T}$ regulatory responses and inhibits autoimmunity. Nat. Med. 15, 401-409. doi: 10.1038/nm.1925

Marrazzo, P., Crupi, A. N., Alviano, F., Teodori, L., and Bonsi, L. (2019). Exploring the roles of MSCs in infections: focus on bacterial diseases. J. Mol. Med. 97, 437-450. doi: 10.1007/s00109-019-01752-6

Marx, C., Gardner, S., Harman, R. M., and Van de Walle, G. R. (2020). The mesenchymal stromal cell secretome impairs methicillin-resistant Staphylococcus aureus biofilms via cysteine protease activity in the equine model. Stem Cells Transl. Med. 9, 746-757. doi: 10.1002/sctm.19-0333

Mascellino, M. T., Boccia, P., and Oliva, A. (2011). Immunopathogenesis in Chlamydia trachomatis Infected Women. ISRN Obstet. Gynecol. 2011:436936. doi: $10.5402 / 2011 / 436936$

Matsumoto, K., Mizoue, K., Kitamura, K., Tse, W. C., Huber, C. P., and Ishida, T. (1999). Structural basis of inhibition of cysteine proteases by E-64 and its derivatives. Biopolymers 51, 99-107. doi: 10.1002/(SICI)1097-0282(1999)51:1\& lt;99::AID-BIP11\&gt;3.0.CO;2-R

McGee, Z. A., Jensen, R. L., Clemens, C. M., Taylor-Robinson, D., Johnson, A. P., and Gregg, C. R. (1999). Gonococcal infection of human fallopian tube mucosa in organ culture: relationship of mucosal tissue TNF-alpha concentration to sloughing of ciliated cells. J. Sex. Transm. Dis. 26, 160-165. doi: 10.1097/ 00007435-199903000-00007

Meisel, R., Brockers, S., Heseler, K., Degistirici, O., Bülle, H., Woite, C., et al. (2011). Human but not murine multipotent mesenchymal stromal cells exhibit broad-spectrum antimicrobial effector function mediated by indoleamine 2,3dioxygenase. Leukemia 25, 648-654. doi: 10.1038/leu.2010.310

Méndez-Samperio, P. (2013). Recent advances in the field of antimicrobial peptides in inflammatory diseases. Adv. Biomed. Res. 2:50. doi: 10.4103/2277-9175. 114192

Mendt, M., Rezvani, K., and Shpall, E. (2019). Mesenchymal stem cell-derived exosomes for clinical use. Bone Marrow Transplant. 54(Suppl. 2), 789-792. doi: 10.1038/s41409-019-0616-z

Menon, S., Timms, P., Allan, J. A., Alexander, K., Rombauts, L., Horner, P., et al. (2015). Human and pathogen factors associated with Chlamydia trachomatisrelated infertility in women. Clin. Microbiol. Rev. 28, 969-985. doi: 10.1128/ CMR.00035-15

Michels, K. R., Zhang, Z., Bettina, A. M., Cagnina, R. E., Stefanova, D., Burdick, M. D., et al. (2017). Hepcidin-mediated iron sequestration protects against bacterial dissemination during pneumonia. JCI Insight 2:e92002. doi: 10.1172/ jci.insight.92002

Momen-Heravi, F., Balaj, L., Alian, S., Mantel, P. Y., Halleck, A. E., Trachtenberg, A. J., et al. (2013). Current methods for the isolation of extracellular vesicles. Biol. Chem. 394, 1253-1262. doi: 10.1515/hsz-2013-014

Morales, P., Reyes, P., Vargas, M., Rios, M., Imarai, M., Cardenas, H., et al. (2006). Infection of human fallopian tube epithelial cells with Neisseria gonorrhoeae protects cells from tumor necrosis factor alpha-induced apoptosis. Infect. Immun. 74, 3643-3650. doi: 10.1128/IAI.00012-06

Morrison, T. J., Jackson, M. V., Cunningham, E. K., Kissenpfennig, A., McAuley, D. F., O’Kane, C. M., et al. (2017). Mesenchymal stromal cells modulate macrophages in clinically relevant lung injury models by extracellular vesicle mitochondrial transfer. Am. J. Respir. Crit. Care Med. 196, 1275-1286. doi: 10.1164/rccm.201701-0170OC

Nikfarjam, S., Rezaie, J., Zolbanin, N. M., and Jafari, R. (2020). Mesenchymal stem cell derived-exosomes: a modern approach in translational medicine. J. Transl. Med. 18:449. doi: 10.1186/s12967-020-02622-3

O'Connell, C. M., and Ferone, M. E. (2016). Chlamydia trachomatis genital infections. Microb. Cell 3, 390-403. doi: 10.15698/mic2016.09.525

Oliveira-Bravo, M., Sangiorgi, B. B., Schiavinato, J. L., Carvalho, J. L., Covas, D. T., Panepucci, R. A., et al. (2016). LL-37 boosts immunosuppressive function of placenta-derived mesenchymal stromal cells. Stem Cell Res. Ther. 7:189. doi: 10.1186/s13287-016-0448-3

Park, J., Kim, S., Lim, H., Liu, A., Hu, S., Lee, J., et al. (2019). Therapeutic effects of human mesenchymal stem cell microvesicles in an ex vivo perfused human lung injured with severe E. coli pneumonia. Thorax 74, 43-50. doi: 10.1136/ thoraxjnl-2018-211576

Patrone, J. B., and Stein, D. C. (2007). Effect of gonococcal lipooligosaccharide variation on human monocytic cytokine profile. BMC Microbiol. 7:7. doi: 10. 1186/1471-2180-7-7

Perrini, C., Strillacci, M. G., Bagnato, A., Esposti, P., Marini, M. G., Corradetti, B., et al. (2016). Microvesicles secreted from equine amniotic-derived cells and their potential role in reducing inflammation in endometrial cells in an in-vitro model. Stem Cell Res. Ther. 7:169. doi: 10.1186/s13287-016-0429-6

Poormasjedi-Meibod, M. S., Jalili, R. B., Hosseini-Tabatabaei, A., Hartwell, R., and Ghahary, A. (2013). Immuno-regulatory function of indoleamine 2,3 dioxygenase through modulation of innate immune responses. PLoS One 8:e71044. doi: 10.1371/journal.pone.0071044

Qian, X., An, N., Ren, Y., Yang, C., Zhang, X., and Li, L. (2021). Immunosuppressive effects of mesenchymal stem cells-derived exosomes. Stem Cell Rev. Rep. 17, 411-427. doi: 10.1007/s12015-020-10040-7

Quillin, S. J., and Seifert, H. S. (2018). Neisseria gonorrhoeae host adaptation and pathogenesis. Nat. Rev. Microbiol. 16, 226-240. doi: 10.1038/nrmicro.2017. 169

Raghav, A., Tripathi, P., Mishra, B. K., Jeong, G. B., Banday, S., Gautam, K. A., et al. (2021). Mesenchymal stromal cell-derived tailored exosomes treat bacteriaassociated diabetes foot ulcers: a customized approach from bench to bed. Front. Microbiol. 12:712588. doi: 10.3389/fmicb.2021.712588

Raicevic, G., Rouas, R., Najar, M., Stordeur, P., Boufker, H. I., Bron, D., et al. (2010). Inflammation modifies the pattern and the function of Toll-like receptors expressed by human mesenchymal stromal cells. Hum. Immunol. 71, 235-244. doi: 10.1016/j.humimm.2009.12.005

Rarick, M., McPheeters, C., Bright, S., Navis, A., Skefos, J., Sebastiani, P., et al. (2006). Evidence for cross-regulated cytokine response in human peripheral blood mononuclear cells exposed to 89 . whole gonococcal bacteria in vitro. Microb. Pathog. 40, 261-270. doi: 10.1016/j.micpath.2006.02.003

Rezaie, J., Aslan, C., Ahmadi, M., Zolbanin, N. M., Kashanchi, F., and Jafari, R. (2021). The versatile role of exosomes in human retroviral infections: from immunopathogenesis to clinical application. Cell Biosci. 11:19. doi: 10.1186/ s13578-021-00537-0

Riazifar, M., Mohammadi, M. R., Pone, E. J., Yeri, A., Lässer, C., Segaliny, A. I., et al. (2019). Stem cell-derived exosomes as nanotherapeutics for autoimmune and neurodegenerative disorders. ACS Nano 13, 6670-6688. doi: 10.1021/acsnano. 9 b01004

Russell, K. A., Garbin, L. C., Wong, J. M., and Koch, T. G. (2020). Mesenchymal stromal cells as potential antimicrobial for veterinary Use-A comprehensive review. Front. Microbiol. 11:606404. doi: 10.3389/fmicb.2020.606404

Sadeghian-Nodoushan, F., Aflatoonian, R., Borzouie, Z., Akyash, F., Fesahat, F., Soleimani, M., et al. (2016). Pluripotency and differentiation of cells from human testicular sperm extraction: An investigation of cell stemness. Mol. Reprod. Dev. 83, 312-323. doi: 10.1002/mrd.22620

Saeedi, P., Halabian, R., and Fooladi, A. A. I. (2019). Mesenchymal stem cells preconditioned by staphylococcal enterotoxin B enhance survival and bacterial clearance in murine sepsis model. Cytotherapy 21, 41-53. doi: 10.1016/j.jcyt. 2018.11.002 
Sellami, H., Said-Sadier, N., Znazen, A., Gdoura, R., Ojcius, D. M., and Hammami, A. (2014). Chlamydia trachomatis infection increases the expression of inflammatory tumorigenic cytokines and chemokines as well as components of the Toll-like receptor and NF-кB pathways in human prostate epithelial cells. Mol. Cell. Probes 28, 147-154. doi: 10.1016/j.mcp.2014.01.006

Song, Y., Dou, H., Li, X., Zhao, X., Li, Y., Liu, D., et al. (2017). Exosomal miR-146a contributes to the enhanced therapeutic efficacy of interleukin-1beta-primed mesenchymal stem cells against sepsis. Stem Cells 35, 1208-1221. doi: 10.1002/ stem.2564

Sun, B., Ma, Y., Wang, F., Hu, L., and Sun, Y. (2019). miR-644-5p carried by bone mesenchymal stem cell-derived exosomes targets regulation of p53 to inhibit ovarian granulosa cell apoptosis. Stem Cell Res. Ther. 10:360. doi: 10.1186/ s13287-019-1442-3

Sun, Y. Q., Zhang, Y., Li, X., Deng, M. X., Gao, W. X., Yao, Y., et al. (2015). Insensitivity of Human iPS cells-derived mesenchymal stem cells to interferon$\gamma$-induced hla expression potentiates repair efficiency of hind limb ischemia in immune humanized NOD Scid Gamma Mice. Stem Cells 33, 3452-3467. doi: 10.1002/stem.2094

Sung, D. K., Chang, Y. S., Sung, S. I., Yoo, H. S., Ahn, S. Y., and Park, W. S. (2016). Antibacterial effect of mesenchymal stem cells against Escherichia coli is mediated by secretion of beta- defensin- 2 via toll- like receptor 4 signalling. Cell. Microbiol. 18, 424-436. doi: 10.1111/cmi.12522

Sutton, M. T., Fletcher, D., Episalla, N., Auster, L., Kaur, S., Gwin, M. C., et al. (2017). Mesenchymal stem cell soluble mediators and cystic fibrosis. J. Stem Cell Res. Ther. 7:400. doi: 10.4172/2157-7633.1000400

Takahashi, Y., Nishikawa, M., Shinotsuka, H., Matsui, Y., Ohara, S., Imai, T., et al. (2013). Visualization and in vivo tracking of the exosomes of murine melanoma B16-BL6 cells in mice after intravenous injection. J. Biotechnol. 165, 77-84. doi: 10.1016/j.jbiotec.2013.03.013

Thennarasu, S., Tan, A., Penumatchu, R., Shelburne, C. E., Heyl, D. L., and Ramamoorthy, A. (2010). Antimicrobial and membrane disrupting activities of a peptide derived from the human cathelicidin antimicrobial peptide LL37. Biophys. J. 98, 248-257. doi: 10.1016/j.bpj.2009.09.060

Théry, C., Witwer, K. W., Aikawa, E., Alcaraz, M. J., Anderson, J. D., and Andriantsitohaina, R. (2018). Minimal information for studies of extracellular vesicles 2018 (MISEV2018): a position statement of the International Society for Extracellular Vesicles and update of the MISEV2014 guidelines. J. Extracell. Vesicles 7:1535750. doi: 10.1080/20013078.2018.1535750

Tsevat, D. G., Wiesenfeld, H. C., Parks, C., and Peipert, J. F. (2017). Sexually transmitted diseases and infertility. Am. J. Obstet. Gynecol. 216, 1-9. doi: 10. 1016/j.ajog.2016.08.008

Velasquez, L., García, K., Morales, F., Heckels, J. E., Orihuela, P., Rodas, P. I., et al. (2012). Neisseria gonorrhoeae pilus attenuates cytokine response of human fallopian tube explants. J. Biomed. Biotechnol. 2012:491298. doi: 10.1155/2012/ 491298

Vizoso, F. J., Eiro, N., Cid, S., Schneider, J., and Perez-Fernandez, R. (2017). Mesenchymal stem cell secretome: toward cell-free therapeutic strategies in regenerative medicine. Int. J. Mol. Sci. 18:1852. doi: 10.3390/ijms1809 1852

Volkova, N., Yukhta, M., and Goltsev, A. (2017). Mesenchymal stem cells in restoration of fertility at experimental pelvic inflammatory disease. Stem Cells Int. 2017:2014132. doi: 10.1155/2017/2014132

Wang, X., Tang, Y., Liu, Z., Yin, Y., Li, Q., Liu, G., et al. (2021). The application potential and advance of mesenchymal stem cell-derived exosomes in myocardial infarction. Stem Cells Int. 2021:5579904. doi: 10.1155/2021/ 5579904

Wei, W., Ao, Q., Wang, X., Cao, Y., Liu, Y., Zheng, S. G., et al. (2021). Mesenchymal stem cell-derived exosomes: a promising biological tool in nanomedicine. Front. Pharmacol. 11:590470. doi: 10.3389/fphar.2020.590470

Williams, A. R., Suncion, V. Y., McCall, F., Guerra, D., Mather, J., Zambrano, J. P., et al. (2013). Durable scar size reduction due to allogeneic mesenchymal stem cell therapy regulates whole-chamber remodeling. J. Am. Heart Assoc. 2:e000140. doi: 10.1161/JAHA.113.000140
Witt, K., Veale, D. R., and Smith, H. (1976). Resistance of Neisseria gonorrhoeae to ingestion and digestion by phagocytes of human buffy coat. J. Med. Microbiol. 9, 1-12. doi: 10.1099/00222615-9-1-1

Xie, M., Xiong, W., She, Z., Wen, Z., Abdirahman, A. S., Wan, W., et al. (2020). Immunoregulatory effects of stem cell-derived extracellular vesicles on immune cells. Front. Immunol. 11:13. doi: 10.3389/fimmu.2020.00013

Xin, L., Lin, X., Zhou, F., Li, C., Wang, X., Yu, H., et al. (2020). A scaffold laden with mesenchymal stem cell-derived exosomes for promoting endometrium regeneration and fertility restoration through macrophage immunomodulation. Acta Biomater. 113, 252-266. doi: 10.1016/j.actbio.2020. 06.029

Yagi, H., Chen, A. F., Hirsch, D., Rothenberg, A. C., Tan, J., Alexander, P. G., et al. (2020). Antimicrobial activity of mesenchymal stem cells against Staphylococcus aureus. Stem Cell Res. Ther. 11:293. doi: 10.1186/s13287-020-01807-3

Yang, B., Good, D., Mosaiab, T., Liu, W., Ni, G., Kaur, J., et al. (2020). Significance of LL-37 on immunomodulation and disease outcome. Biomed Res. Int. 2020:8349712. doi: 10.1155/2020/8349712

Yang, K., Wu, Y., Xie, H., Li, M., Ming, S., Li, M., et al. (2016). Macrophagemediated inflammatory response decreases mycobacterial survival in mouse MSCs by augmenting NO production. Sci. Rep. 6:27326. doi: 10.1038/srep27326

Yuan, Q. L., Zhang, Y. G., and Chen, Q. (2020). Mesenchymal stem cell (MSC)derived extracellular vesicles: potential therapeutics as msc trophic mediators in regenerative medicine. Anat. Rec. 303, 1735-1742. doi: 10.1002/ar.24186

Zhang, B., Yeo, R. W., Tan, K. H., and Lim, S. K. (2016). Focus on extracellular vesicles: therapeutic potential of stem cell-derived extracellular vesicles. Int. J. Mol. Sci. 17:174. doi: 10.3390/ijms17020174

Zhang, Q., Sun, J., Huang, Y., Bu, S., Guo, Y., Gu, T., et al. (2019). Human amniotic epithelial cell-derived exosomes restore ovarian function by transferring MicroRNAs against apoptosis. Mol. Ther. Nucleic Acids 16, 407-418. doi: 10. 1016/j.omtn.2019.03.008

Zhang, Y., Bi, J., Huang, J., Tang, Y., Du, S., and Li, P. (2020). Exosome: a review of its classification, isolation techniques, storage, diagnostic and targeted therapy applications. Int. J. Nanomedicine 15, 6917-6934. doi: 10.2147/IJN.S264498

Zhao, S., Qi, W., Zheng, J., Tian, Y., Qi, X., Kong, D., et al. (2020). Exosomes derived from adipose mesenchymal stem cells restore functional endometrium in a rat model of intrauterine adhesions. Reprod. Sci. 27, 1266-1275. doi: 10. 1007/s43032-019-00112-6

Zhu, W., Ventevogel, M. S., Knilans, K. J., Anderson, J. E., Oldach, L. M., McKinnon, K. P., et al. (2012). Neisseria gonorrhoeae suppresses dendritic cellinduced, antigen-dependent CD4 T cell proliferation. PLoS One 7:e41260. doi: 10.1371/journal.pone.0041260

Zhu, Y. G., Feng, X. M., Abbott, J., Fang, X. H., Hao, Q., Monsel, A., et al. (2014). Human mesenchymal stem cell microvesicles for treatment of Escherichia coli endotoxin-induced acute lung injury in mice. Stem Cells 32, 116-125. doi: $10.1002 /$ stem. 1504

Conflict of Interest: The authors declare that the research was conducted in the absence of any commercial or financial relationships that could be construed as a potential conflict of interest.

Publisher's Note: All claims expressed in this article are solely those of the authors and do not necessarily represent those of their affiliated organizations, or those of the publisher, the editors and the reviewers. Any product that may be evaluated in this article, or claim that may be made by its manufacturer, is not guaranteed or endorsed by the publisher.

Copyright (c) 2022 Zohrabi, Dehghan Marvast, Izadi, Mousavi and Aflatoonian. This is an open-access article distributed under the terms of the Creative Commons Attribution License (CC BY). The use, distribution or reproduction in other forums is permitted, provided the original author(s) and the copyright owner(s) are credited and that the original publication in this journal is cited, in accordance with accepted academic practice. No use, distribution or reproduction is permitted which does not comply with these terms. 